Intensive care

\section{Neonatal long lines}

\section{G Menon}

\section{Are they safe?}

C entral venous (CV) lines have been the subject of much professional debate and public exposure in the UK following an enquiry into the deaths of four children in Manchester as the result of cardiac tamponade. One of the recommendations of this review was that CV line tips should not be placed within the cardiac outline. ${ }^{1}$ This has been the recommendation of $\mathrm{CV}$ line manufacturers for some time.

In this issue, Beardsall et al report a retrospective questionnaire survey of pericardial effusion (PCE) and tamponade associated with percutaneously inserted central lines, together with a survey of current practice in percutaneously inserted central line use in neonatal units around the UK. ${ }^{2}$ They compare the incidence of PCE in units with different approaches to the use of percutaneously inserted central lines. Despite likely ascertainment and response bias, and unknown confounders, this study adds an important piece to the complex puzzle of PCE. Their incidence of PCE of $1.8 \%$ in percutaneously inserted central lines is at the upper end of that reported in case series of $0.5-2.0 \% .^{3}$ Most PCE occurred in units aiming to place the line tip in the caval veins; the risk was greatest in units with the lowest use of CV lines. The most important conclusion of this study is that, with the current approach to positioning of long lines, an attempt to site the line tip in the caval veins (rather than the right atrium) is not associated with a reduction in incidence of PCE.

\section{TYPES OF CV LINE}

Several types of CV line are used in neonatal care:

(1) Umbilical venous catheters (UVC)

(2) Peripherally inserted central lines

(3) Central lines inserted over a guide wire at puncture of a large superficial vein

(4) Surgically inserted central lines.

\section{Umbilical venous catheters}

These are relatively easy to insert in the newborn and have been used in sick neonates for a long time. They are generally 3-5 Fr gauge and made of poly(vinyl chloride) (PVC) or polyurethane. Multiple lumen UVCs have been used to reduce the need for peripheral venous access in very sick and in extremely preterm infants. ${ }^{4}$

\section{Peripherally inserted central lines} These are made of silicone or polyurethane and are used commonly in neonates. Several developments have made the insertion technique easier: the two piece catheter joined by a hub, the peelable needle or cannula, and narrower gauge catheters.

\section{Central lines inserted over a guide wire}

These are usually placed at puncture of one of the neck veins or the femoral vein.

\section{Surgically inserted central lines}

These are inserted after direct cut down-this is usually done using a Hickman or Broviac catheter into a jugular vein.

\section{REASONS FOR THE USE OF CV LINES}

There are several reasons for the use of $\mathrm{CV}$ lines in neonatal care:

(1) To provide secure venous access for administration of fluids and parenteral nutrition (PN) when it seems likely that full enteral nutrition will not be possible for some time.

(2) To enable the safe and uninterrupted administration of clinically essential or locally toxic solutions (for example, inotropes or concentrated dextrose solution).

(3) As a mode of venous access when peripheral options have been exhausted.

Larger bore lines can be used for other purposes such as exchange transfusion, central venous pressure monitoring, cardiac catheterisation, extracorporeal membrane oxygenation, and haemofiltration

\section{RISKS ASSOCIATED WITH CV LINE USE}

As the options for central venous access increase, and CV lines become technically easier for a novice to insert at the cot side, their risks should not be forgotten, and neonatologists should be on guard against inappropriate use. CV lines have been implicated in the causation of many different problems.

\section{Direct tissue injury}

Direct tissue injury at insertion is most likely with guide wire aided insertion, with blind needling of a chest vein, and with dilators sometimes used for Hickman lines. This may result in pneumothorax or injury to the heart or great vessels resulting in a pericardial or pleural effusion, stroke from carotid artery injury, or mediastinitis. PCE is nearly always bloodless, and is probably the result of the accumulation of infused fluid in the pericardium. This risk may be reduced by ultrasound or fluoroscopy guidance at insertion. Vascular perforation can also happen with UVCs whose larger bore makes them intrinsically less elastic. ${ }^{56}$ The newer polyurethane lines soften following insertion, while PVC lines tend to become stiffer, probably because of leaching of plasticiser (the latter cost less and substantial numbers are still used ${ }^{7}$ ).

\section{Intravascular thrombosis}

This is probably common, and is frequently associated with line related sepsis. ${ }^{8}$ It may result in pulmonary embolism or a vena cava syndrome. The complication appears to be more common with the catheter tip in the right atrium in adults.

\section{Embolism}

Air embolism, probably the result of leakage into a disconnected line, ${ }^{10}$ and embolisation of catheter fragments, with or without obvious trauma, ${ }^{11}$ have been described.

\section{Risks of parenteral nutrition}

The many risks of parenteral nutrition accompany the use of long lines for feeding. The high osmolarity of amino acid-glucose solutions may increase the risk of effusion by damaging the vascular wall.

\section{Line related sepsis}

This is probably the commonest serious complication of long lines. ${ }^{12}$ The incidence of line related sepsis appears to be 4-12 per 1000 catheter days. Its risk is increased by longer duration of catheterisation, and is probably influenced by catheter material, frequency of line breaks for infusion change and drug injection, the presence of multiple lumens, and by technique of catheter fixation. Line sepsis is frequently accompanied by thrombus formation. The rate of infection can be reduced by staff education. ${ }^{13}$ Incorporation in CV lines of heparin, silver, or other substances with

Abbreviations: $C V$, central venous; $P C E$, pericardial effusion; $P N$, parenteral nutrition; PVC, poly(vinyl chloride); UVC, umbilical venous catheter 
antimicrobial qualities has shown promise in adult studies, but has not been investigated in the paediatric population..$^{14}$

\section{Delayed effusion}

Delayed effusion into a body cavity can occur, probably because of damage to the vascular wall by infused fluid. It may develop after a catheter (usually a fine bore peripherally inserted central line) passes into a small vein and then causes extravasation. Hypoglycaemia caused by interruption of the intravenous infusion may provide a clue to the problem. Accumulation of infusate has been described in the subarachnoid space (line tip in the lumbar plexus ${ }^{15}$ ), renal pelvis (renal veins ${ }^{16}$ ), peritoneal cavity, retroperitoneal space or externally from the abdominal wall (epigastric vein ${ }^{17}$ ) with lower limb lines, and in the pleural space (pulmonary veins ${ }^{18}$ ) with upper limb lines. Obtaining $x$ ray pictures in more than one plane may be useful for positioning lower limb peripherally inserted central lines, although only repeated imaging will pick up catheter migration after insertion. ${ }^{19}$

Pleural and pericardial effusion may develop after an interval with the line tip in the superior vena cava or atrium of the heart. ${ }^{20}$ There is uncertainty about the pathogenesis of this complication. It probably results from erosion of the vascular or cardiac wall, with or without prior intravascular catheter migration. The risk appears to be greatest when the end of the catheter creates an acute angle to the vessel or cardiac wall. This may then cause injury because a jet of abrasive fluid is directed at a small area of the wall, assisted by reactive thrombus attaching the catheter tip to the endothelium. This is most likely with: (a) a redundant length of free catheter in the heart (for PCE); or (b) a catheter tip in the left innominate vein at its junction with the superior vena cava (for pleural effusion). ${ }^{21}$

\section{PCE with tamponade}

This is a rare complication, associated with a high mortality, partly because of delayed recognition. Nowlen et al recently described 14 cases in six Texas neonatal units and reviewed 47 in the literature, detailing their clinical characteristics. ${ }^{3}$ PCE occurred in $0.5-2 \%$ of CV lines, with an effusion similar in composition to the infusate in the vast majority. The median time from CV line insertion to presentation was 3 days (range 0-37), with nearly two thirds presenting as sudden cardiovascular collapse, and most of the rest having unexplained cardiorespiratory instability. At pathology, there may be associated vascular wall inflammation and thrombosis, with or without perforation. It appears likely that there are two mechanisms involved: (1) perforation at the time of insertion ${ }^{22}$; and (2) slow damage to the integrity of the vascular wall, resulting in either transmural diffusion of infusate or erosion of the line into the pericardial space. Several case reports describe a coexisting bacteraemia, and one an active pericarditis. ${ }^{23}$ PCE is most commonly described with catheter tips placed within the heart outline on $x$ ray examination, when endocardial damage from a fluid jet from looped catheter is the likely explanation. ${ }^{24}$ Extracardiac positioning does not, however, abolish the risk of $\mathrm{PCE},{ }^{20}$ probably because the pericardial reflection extends some way along the caval veins. ${ }^{25}$ The neonatal cardiac atria are probably easier to damage than in an older heart, with some areas having little muscle. The risk of effusion may be increased with upper limb CV lines because the position of the line tip changes considerably with arm position (up to $15 \mathrm{~mm}$ movement without any change in length of intravascular catheter). ${ }^{26}$ This has been said to justify strict arm positioning prior to $x$ ray examination. There may be migration of the catheter with time. ${ }^{19}$ However, periodic $x$ ray examinations do not seem justified in view of the dangers associated with the significant handling involved, including inadvertent dislodgement of the endotracheal tube and other intensive care equipment. In addition, adjustment of a central line after it is secured may threaten its integrity and security of fixation. Surgically inserted lines are cut to an estimated length prior to insertion, and are particularly difficult to adjust later because they have a subcutaneous cuff and a very short intravascular portion.

\section{POSITIONING OF CV LINES}

$x$ Ray pictures give limited information about line positioning because of the difficulty of naked eye discrimination of catheter and soft tissues, and the inability of a 2D image to illustrate the complex 3D structure of the heart and great vessels. Contrast injection may under- or overestimate catheter length, because the catheter may be either partially filled or extrude a jet of contrast from the tip at the time of the $x$ ray examination. There may be a case for the more widespread use of ultrasound ${ }^{27}$ and intravascular $\mathrm{ECG}^{28}$ to aid placement of CV lines. Manipulation of digitised images may also make line tip identification easier.

We must not become fixated on avoiding intracardiac positioning of lines and let this distract from other equally important issues in line positioning, and the more common complications of long lines. The controversy about line placement is not unique to neonatology-a recent editorial in an anaesthetic journal provides a balanced and sensible argument. $^{29}$

\section{ARE LONG LINES SAFE?}

The provocative question of the title remains to be answered: "Are long lines safe?" Of course they are not. There are very real dangers associated with introducing a plastic line through the bacteria colonised skin of an infant into its central circulation, and then infusing a concentrated mixture of sugar, amino acids, and lipids.

Conversely, are they so dangerous that their use should be centrally governed or restricted? I would argue, no. In a baby at the borderline of viability, with fragile skin and vessels, who may need parenteral nutrition for more than two weeks, a long line may be a "lifeline" on which survival depends. The decision about inserting a long line in an individual baby is a difficult one, and like many clinical decisions involves balancing the unique risks and benefits. If we consider long lines for feeding, there are many imperfectly quantified risks affecting the choice of feeding route and method. ${ }^{30}$ These risks depend among other things on gestation, postnatal age, the degree of illness of the baby, the other invasive treatments used, the type of milk available for feeding, the type of line used, the position of the line tip, and the duration of line use. The alternative to the use of a long line is the use of peripheral venous cannulae, an approach which is associated with more frequent interruptions to nutrient supply when cannulae fail and an appreciable risk of permanent scarring from extravasation injury. ${ }^{31}$

There is no explicit professional consensus on CV line insertion technique, method of fixation, indications for removal, or the need for parental information or consent. The potential for inconsistency is compounded by the problems with practical training created by the shift working of junior doctors. I would therefore suggest a requirement for:

(1) Practical/video instruction at induction for junior staff about central lines

(2) Clear local guidelines for the use of central lines and related clinical processes, including feeding

(3) Consultant decision about insertion and removal of central lines and daily consultant review of any baby with such a line.

I believe that long lines should not be used when such supervision is not possible. Greater senior involvement in decision making is probably preferable to the imposition of national guidelines, which would of necessity be somewhat arbitrary.

There is a need for further research (mechanism of complications, effect of 
Summary

- Central venous lines provide secure vascular access in newborn infants, but are associated with many serious complications

- Line related sepsis, the commonest of these, may be minimised by using polyurethane or silicone CV lines, minimising line breaks, using single rather than multiple lumen lines, shortening duration of use, and staff education

- Extravasation probably occurs as the result of the catheter tip being in a small vein or pointing at the wall of a large vessel or cardiac chamber

- Pericardial effusions resulting in tamponade may be more likely when the catheter tip lies within the cardiac silhovette, particularly if there is a length of free catheter within the heart

- Positioning the line tip outside the heart does not completely prevent cardiac tamponade and may cause other serious complications

- Early signs of pericardial effusion should be recognised, including unexplained cardiovascular decompensation and enlarging cardiac silhouette on $x$ ray examination

- Long lines should, where possible, be repositioned until the tip is outside the cardiac silhovette, avoiding small vessels and acute angles between catheter and vascular wall, with final tip position confirmed by $x$ ray examination or ultrasound

- Parents should be informed about planned long line insertion, and individual units should consider formal consent

- There should be senior involvement in the supervision of long line use, the setting up of feeding guidelines, and staff education

line tip position, optimum imaging technique, effect of infused fluids) and surveillance/audit of practice. There should be a national survey of long line use and associated complications, documenting every long line used and, ideally, all insertion attempts. Such a venture could involve a survey insert in the packaging of CV lines, which was returned when the line was removed. As part of such a survey, long lines should be left in situ for postmortem examinations, since in many case reports of complications an inference is made about catheter tip position from imaging done some time before clinical deterioration.

The publicity relating to the Manchester enquiry and other incidents has led to criticism of the paternalistic approach of the health service. This should make us question the indications for the invasive procedures we carry out, and our approach to parental information and consent. Formal consenting may be appropriate for the planned insertion of long lines and for other treatments which are non-urgent, especially if they are of disputed benefit and if controversy has reached public awareness. We may have to accept an accompanying increase in parental anxiety and a greater need for parental counselling and support.

Although they are now an essential element of neonatal care, CV lines are associated with serious complications, and should only be used with caution and experienced supervision. Positioning the tip outside the cardiac silhouette will not eliminate the risk of cardiac tamponade and no line tip position will avoid all serious complications. Once a line has been inserted, there should be regular review to justify its continued use.

\section{ACKNOWLEDGEMENTS}

I would like the thank my colleagues Ian Laing, Andy Lyon, and Ben Stenson who looked at draft versions of this article, and Gordon MacKinlay, Bill Manson, and Fraser Munro who provided surgical expertise.

Arch Dis Child Fetal Neonatal Ed 2003;88: F260-F262

\section{Author's affiliation}

G Menon, Neonatal Unit, Simpson Centre for Reproductive Health, Royal Infirmary of Edinburgh, UK

Correspondence to: $\operatorname{Dr} G$ Menon, Neonatal Unit, Simpson Centre for Reproductive Health, Royal Infirmary of Edinburgh, 51 Little France Crescent, Old Dalkeith Road, Edinburgh EH16 4SU, UK; gopi.menon@luht.scot.nhs.uk

\section{REFERENCES}

1 Department of Health. Review of four neonatal deaths due to cardiac tamponade associated with the presence of a central venous catheter. London: HMSO, 2001

2 Beardsall K, White DK, Pinto EM, et al. Pericardial effusions and cardiac tamponade as complications of neonatal long lines: are they really a problem? Arch Dis Child Fetal Neonatal Ed 2003:88:292-5.

3 Nowlen TT, Rosenthal GL, Johnson GL, et al. Pericardial effusion and tamponade in infants with central catheters. Pediatrics 2002; 110:137-42.

4 Khilnani P, Goldstein B, Todres ID. Double lumen umbilical venous catheters in critically ill neonates: a randomized prospective study Crit Care Med 1991;19:1348-51.

5 Chatel-Meijer MP, Roques-Gineste M, Fries $F$, et al. [Cardiac tamponade secondary to umbilical venous catheterization accident in a premature infant]. Arch Fr Pediatr 1992;49:373-6.

6 Kanto WP Jr, Parrish RA Jr. Perforation of the peritoneum and intra-abdominal hemorrhage: a complication of umbilical vein catheterizations. Am J Dis Child 1977;131:1102-3.

7 Vygon UK. Personal communication, 2002.

8 Mehta S, Connors AF Jr, Danish EH, et al. Incidence of thrombosis during central venous catheterization of newborns: a prospective study. J Pediatr Surg 1992;27: 18-22.

9 Gilon D, Schechter D, Rein AJ, et al. Right atrial thrombi are related to indwelling central venous catheter position: insights into time course and possible mechanism of formation. Am Heart J 1998;135:457-62.

10 Inamasu J, Nakamura Y, Saito R, et al. Cerebral air embolism after central venous catheterization. Am J Emerg Med 2001;19:520-1.

11 Ochikubo CG, O'Brien LA, Kanakriyeh M, et al. Silicone-rubber catheter fracture and embolization in a very low birth weight infant J Perinatol 1996;16:50-2.

12 Mahieu LM, De Muynck AO, leven MM, et al. Risk factors for central vascular catheter-associated bloodstream infections among patients in a neonatal intensive care unit. J Hosp Infect 2001;48:108-16.

13 Coopersmith CM, Rebmann TL, Zack JE, et al. Effect of an education program on decreasing catheter-related bloodstream infections in the surgical intensive care unit Crit Care Med. 2002;30:59-64.

14 Mermel LA. Prevention of intravascular catheter-related infections. Ann Intern Med 2000; 132:391-402

15 Kelly MA, Finer NN, Dunbar LG. Fatal neurologic complication of parenteral feeding through a central vein catheter. Am J Dis Child 1984; 138:352-3

16 Nadroo AM, al Sowailem AM. Extravasation of parenteral alimentation fluid into the renal pelvis - a complication of central venous catheter in a neonate. J Perinato 2001;21:465-6.

17 Baker J, Imong S. A rare complication of neonatal central venous access. Arch Dis Child Fetal Neonatal Ed 2002;86:F61-F62.

18 Madhavi P, Jameson R, Robinson $\mathrm{W}$. Unilateral pleural effusion complicating central venous catheterisation. Arch Dis Child Fetal Neonatal Ed 2000;82:F248-F249.

19 Currarino G. Migration of jugular or subclavian venous catheters into inferior tributaries of the brachiocephalic veins or into the azygos vein, with possible complications. Pediatr Radiol 1996;26:439-49.

20 Keeney SE, Richardson CJ. Extravascular extravasation of fluid as a complication of central venous lines in the neonate. J Perinatol 1995; 15:284-8

21 Duntley P, Siever J, Korwes ML, et al. Vascular erosion by central venous catheters. Clinical features and outcome. Chest 1992;101:1633-8.

22 Murray BH, Cohle SD, Davison P. Pericardia tamponade and death from Hickman catheter perforation. Am Surg 1996;62:994-7.

23 Lawrenz-Wolf B, Herrmann B. [Pericardial tamponade caused by catheter infection in an extremely small premature infant]. Monatssch Kinderheilkd 1993;141:932-5.

24 Darling JC, Newell SJ, Mohamdee O, et al. Central venous catheter tip in the right atrium: a risk factor for neonatal cardiac tamponade. J Perinatol 2001;21:461-4.

25 Schuster M, Nave H, Piepenbrock S, et al. The carina as a landmark in central venous catheter placement. Br J Anaesth 2000;85: 192-4

26 Nadroo AM, Glass RB, Lin J, et al. Changes in upper extremity position cause migration of peripherally inserted central catheters in neonates. Pediatrics 2002:110:131-6.

27 Madar RJ, Deshpande SA. Reappraisal of ultrasound imaging of neonatal intravascular catheters. Arch Dis Child Fetal Neonatal Ed 1996;75:F62-F64.

28 Biban P, Cavalli C, Santuz P, et al. [Positioning of umbilical vein catheter with ECG-guided technique: randomized study] Acta Biomed Ateneo Parmense 2000;71(suppl 1):647-50.

29 Anon. Editorial II: Safe placement of central venous catheters: where should the tip of the catheter lie? Br J Anaesth 2000;85: 188-91.

30 Williams AF. Early enteral feeding of the preterm infant. Arch Dis Child Fetal Neonatal Ed 2000;83:F219-F220.

31 Ainsworth SB, Furness J, Fenton AC. Randomized comparative trial between percutaneous longlines and peripheral cannulae in the delivery of neonatal parenteral nutrition. Acta Paediatr 2001;90:1016-20. 